\title{
Evaluation of Lipid Profile in Patients with Cardiovascular Diseases Receiving Simvastatin in Palu Indonesia
}

\author{
Safarudin, Alwiyah Mukaddas, Faraditha Amalia and Amelia Rumi*
}

Department of Pharmacy, Mathematics and Natural Sciences of Faculty, Tadulako University, Indonesia

\begin{abstract}
Cardiovascular diseases (CVDs) are the leading cause of death worldwide which results from the impaired function of the heart and blood vessels. The most common CVDs are coronary heart and stroke. The main clinical manifestation of these diseases is the formation of atherosclerosis which is associated with the change of blood lipid levels. Simvastatin is widely used in patients with impaired lipid levels in the blood. The study was a descriptive research with a retrospective approach on medical record data $(n=64)$ taken from Palu City, Central Sulawesi, Indonesia. The variables included in this study were gender, age, diagnosis, co-medication, lipid profile including total cholesterol, LDL, triglycerides, and HDL in patients with CVDs receiving simvastatin. In the study, sixty-four patients of CVDs met the inclusion and exclusion criteria. This study suggested that simvastatin achieved to normalize the blood lipid levels, including total cholesterol in forty-four patients $(68.75 \%)$, LDL in forty-nine patients $(80.3 \%)$, triglycerides in fifty-nine patients $(92.19 \%)$, and HDL in fifty-two patients $(81.25 \%)$. The use of simvastatin in patients with CVDs managed to lower total cholesterol, LDL, and triglycerides, as well as increase the HDL level.
\end{abstract}

Keywords: Lipid profile, Simvastatin, Cardiovascular diseases.

\section{INTRODUCTION}

Cardiovascular diseases (CVDs) are illnesses with symptoms that include cardiac and artery disorders. Coronary artery disease and stroke are the most common type of CVDs found [1]. According to World Health Organization (2016) [2], CVDs are the leading determinant of mortality worldwide. It has caused approximately $31 \%$ of deaths all over the world $(82 \%$ in developing countries, and $37 \%$ in developed countries). An estimated 17.5 million people die from these diseases each year.

Increasing levels of LDL Cholesterol is correlated with rises in coronary artery risk, while high HDL cholesterol appears to act as a protective factor against coronary artery disease [3]. Metabolic abnormalities involving an increase in plasma lipoprotein concentration are called hyperlipoproteinemia or hyperlipidemia. One of the major clinical manifestations of hyperlipidemia is atherosclerosis that may lead to serious health illnesses such as coronary heart disease and stroke [4]. The prevalence of hyperlipidaemia increases with age. According to the data from the National Health and Nutrition Examination Survey (NHANES), $52.9 \%$ of people with Hiperlipidemia among whom $11.7 \%$ of adults aged $20-39$, and $41.2 \%$ of adults aged 40 to 64 , had increased low-density lipoprotein cholesterol (LDL-C). But only $10.6 \%$ of

\footnotetext{
*Address correspondence to this author at the Department of Pharmacy, Mathematics and Natural Sciences of Faculty, Tadulako University, Palu City, Central Sulawesi, Indonesia; Tel: (0451) 422611 psw 365;

E-mail: amelia@untad.ac.id
}

adults aged $20-39$, and $47.7 \%$ of adults ages 40 to 64 with hyperlipidemia are on treatment.

According to the Ministry of Health (2013) [5], the prevalence of $\mathrm{CHD}$ in Indonesia based on the clinical diagnoses was $0.5 \%$ or an estimated 883,447 people; based on a clinical and/or symptom-related diagnoses, $1.5 \%$ or $2,650,340$ people had CHD. In Central Sulawesi, a diagnosis of $0.8 \%$ is estimated or approximately 14,888 cases, based on a clinical and/or symptom-related diagnoses it was $3.8 \%$ or 70,719 cases.

Statin is one of the lipid-lowering agents available to treat the disease. Statin can reduce LDL levels which is believed can effectively reduce the risk of coronary artery disease [6]. The most common statin drug used to decrease plasma lipids is simvastatin.

In Palu City, the incidence of patients with CVDs each year increases vividly. Therefore the evaluation of lipid profiles of CVDs patients receiving simvastatin is a very important indicator in assessing the effectiveness of therapeutic outcomes of the drug.

\section{METHODS}

The study was a descriptive study in which data was collected retrospectively on medical record data of CVDs from patients in a private hospital in Palu City, Central Sulawesi, Indonesia.

We collected data of patients with any CVDs who were receiving single antihyperlipidemic agent or 
combinations. Patients included needed to have a complete laboratory data including blood lipid profile (total cholesterol, trygliserides, HDL dan LDL). The variables included in this study were gender, age, diagnosis, co-medication, lipid profile including total cholesterol, LDL, triglycerides, and HDL in patients with CVDs receiving simvastatin.

\section{RESULT}

\subsection{Demographic Characteristics}

Based on the data in Table 1, as many as 116 medical records all patients diagnosed with cardiovascular diseases, 64 medical records of patients that met the inclusion criteria and 52 medical records of patients did not meet this criteria, there by discharge because not adequate as be sampled. Results showed that of 64 patients with cardiovascular diseases were male ie 48 people $(75 \%)$ and female 16 people $(25 \%)$, that was evidence that patients suffering from the highest cardiovascular diseases are experienced by men. In this study, the highest cardiovascular diseases patients in patients entered the age range was 55-64 years, ie 23 people (35.4\%) and age group 45-54 were 18 people $(29.2 \%)$.

Table 1: Characteristic of Cardiovascular Diseases Patients in Palu City

\begin{tabular}{|lc|c|c|}
\hline \multicolumn{2}{|c|}{ Patient Characteristic } & Amount $(\mathbf{n}=\mathbf{6 4})$ & Percentage (\%) \\
\hline \hline Sex & & & \\
& Male & 48 & 75 \\
& Female & 16 & 25 \\
& & & \\
& $15-24$ & 1 & 1,5 \\
& $25-34$ & 1 & 1,5 \\
& $35-44$ & 3 & 4,6 \\
& $45-54$ & 18 & 29,2 \\
& $55-64$ & 23 & 35,4 \\
& $\geq 65$ & 18 & 27,7 \\
\hline
\end{tabular}

\subsection{Clinical Characteristic}

\subsubsection{Diagnoses}

In Table 2, a main diagnosis of the biggest cardiovascular diseases suffered in a Palu city hospital is CHF $(32.81 \%)$, followed by STEMI $(20.31 \%)$ and CHD (15.63\%).

\subsubsection{Co-Medication}

The co-medication given to cardiovascular patients were presented in Table 3, the treated of statin group ie simvastatin was the most widely used drug, which was $10.4 \%$ which simvastatin was treated in patients to provide a protective effect on cardiovascular disease patients followed by isosorbit dinitrate $(10.2 \%)$ treated for antiangina and the use of clopidogrel and aspirin $(9.06 \%)$ used as antiplatelet. Then the use of furosemide $(8.9 \%)$ treated extensively for the treatment of CHF (Congestive Heart Failure).

Table 2: The Main Diagnoses of CVDs in Palu City

\begin{tabular}{|c|c|c|}
\hline Primary diagnosis & $\begin{array}{c}\text { Number of } \\
\text { Patients (n=64) }\end{array}$ & Presentation (\%) \\
\hline \hline ACS & 2 & 3.13 \\
\hline STEMI & 13 & 20.31 \\
\hline STEMI Inferior & 2 & 3.13 \\
\hline CHD & 10 & 15.63 \\
\hline CHF & 21 & 32.81 \\
\hline NSTEMI & 4 & 6.25 \\
\hline HT GR II & 2 & 3.13 \\
\hline CAD & 3 & 4.69 \\
\hline IMA & 2 & 3.13 \\
\hline Aritmia Cardis & 2 & 3.13 \\
\hline UAP & 2 & 3.13 \\
\hline OMI Inferior & 1 & 1.56 \\
\hline
\end{tabular}

Notes: ACS=Acute Coronary Syndrome, STEMI=ST-Elevation Myocardial Infarction, $\mathrm{CHD}=$ Congenital Heart Diseases, $\mathrm{CHF}=$ Congestive Heart Failure, $\mathrm{HTN}=$ Hypertension, $\mathrm{CAD}=$ Coronary Artery Disease, $\mathrm{AMl}=$ Acute Myocardial Infarction, UAP=Unstable Angina Pectoris, OMI= Old Infark Miokard.

\subsubsection{Evaluation of Blood Lipid Profile}

Table 4 showed that of 7 people of patients undergoing $<1$ month, all baseline cholesterol examinations of patients were elevated, and all patients had hyperlipidemia. Furthermore, from the evaluation of total cholesterol examination found as many as 3 people decreased cholesterol levels. The same happened in patients who do 1-2 months checks as many as 57 people, found all the baseline examination of total cholesterol patients increased and all also experienced hyperlipidemia. However, after the evaluation of total cholesterol examination more than 41 people had decreased level of total cholesterol. For LDL examination data of patients who do $<1$ month of examination that is as many as 7 people, all of whom have hyperlipidemia with baseline examinations of elevated LDL levels. Then the evaluation examined the decrease in LDL levels in patients as many as 5 people. In patients who performed a 1-2 month check up with baseline LDL levels of patients who had elevated and those with hyperlipidemia were 40. After the evaluation examined there was a decrease LDL 
Table 3: Concomitant Medications Received by the Patients

\begin{tabular}{|c|c|c|c|c|}
\hline Therapy Class & Class & Drugs & Number of Patients $(n=618)$ & Percentage (\%) \\
\hline \multirow{15}{*}{ CVDs Treatments } & Statin & Simvastatin & 64 & 10.4 \\
\hline & Salicylate & Aspirin & 56 & 9.06 \\
\hline & ADP antagonis & Clopidogrel & 56 & 9.06 \\
\hline & Nitrate & Isosorbide dinitrate & 63 & 10.2 \\
\hline & Heart digitalis & Digoxin & 2 & 0.32 \\
\hline & \multirow{2}{*}{ (Calcium Chanel Bloker) CCB } & Amlodipin & 26 & 4.21 \\
\hline & & Dlitiazem & 1 & 0.16 \\
\hline & \multirow{2}{*}{$\begin{array}{l}\text { (Angiotensin Converting Enzim } \\
\text { Inhibitor) ACE inhibitor }\end{array}$} & Kaptopril & 13 & 2.1 \\
\hline & & Lisinopril & 6 & 0.97 \\
\hline & (Angiotensin ReseptorBloker) & Candesartan & 15 & 2.43 \\
\hline & ARB & Valsartan & 4 & 0.65 \\
\hline & Beta blocker & Bisoprolol & 8 & 1.29 \\
\hline & Aldosterone antagonist & Spironolactone & 16 & 2.59 \\
\hline & Solid Diuretics & Furosemide & 55 & 8.9 \\
\hline & Tiazid Diuretics & Hydrochlorothiazide & 1 & 0.16 \\
\hline \multirow{6}{*}{$\begin{array}{l}\text { Antipyretic and } \\
\text { Anti-inflammatory } \\
\text { Analgesics }\end{array}$} & Antitussive & Codeine & 3 & 0.49 \\
\hline & Non opioid analgesics & Paracetamol & 5 & 0.81 \\
\hline & \multirow{3}{*}{ Non-steroidal anti-inflammatory } & Meloxicam & 8 & 1.29 \\
\hline & & Ketolorac & 1 & 0.16 \\
\hline & & Diclofenac Sodium & 2 & 0.32 \\
\hline & Corticosteroid & Methyl prednisolone & 1 & 0.16 \\
\hline \multirow{6}{*}{$\begin{array}{l}\text { Antireflux and } \\
\text { antiulseration }\end{array}$} & Antacids & Antacids & 4 & 0.65 \\
\hline & \multirow{2}{*}{ Histamine Antagonists 2} & Ranitidine & 5 & 0.81 \\
\hline & & Cimetidine & 2 & 0.32 \\
\hline & \multirow{2}{*}{ Proton Pump Inhibitors } & Omeprazole & 40 & 6.47 \\
\hline & & Lansoprazole & 28 & 4.53 \\
\hline & Mucoprotector & Sucralfate & 2 & 0.32 \\
\hline & Mucolitics & Ambroxol & 7 & 1.13 \\
\hline & Colagogum & Lactulose & 9 & 1.46 \\
\hline \multirow{2}{*}{ Antiemetics } & Antagonis reseptor dopamine & Domperidon & 1 & 0.16 \\
\hline & 5-HT3 serotonin antagonists & Ondensentron & 2 & 0.32 \\
\hline \multirow{3}{*}{ Antidiabetic } & Insulin & Insulin Aspart & 8 & 1.29 \\
\hline & Biguanida & Metformin & 11 & 1.78 \\
\hline & Sulfonylureas & Glipirid & 1 & 0.16 \\
\hline Antianxietas & Benzodiazepines & Alprazolam & 29 & 4.69 \\
\hline \multirow{3}{*}{ Antibiotics } & \multirow{3}{*}{ Cephalosporins } & Sefixim & 1 & 0.16 \\
\hline & & Ciprofloxacin & 1 & 0.16 \\
\hline & & Ceftriaxone & 5 & 0.81 \\
\hline \multirow[b]{3}{*}{ Herb } & Anticlips & Fondaparinuks sodium & 20 & 3.24 \\
\hline & \multirow[b]{2}{*}{ Hepatoprotector } & Curcuma & 2 & 0.32 \\
\hline & & $\begin{array}{c}\text { Fructuss chizandra } \\
\text { ekstract }\end{array}$ & 2 & 0.32 \\
\hline \multicolumn{2}{|r|}{ Antivertigo } & Betahistin mesilate & 4 & 0.65 \\
\hline Bronchodilator & Agonisreseptor $\beta 2$ & Salbutamol & 1 & 0.16 \\
\hline \multirow{2}{*}{\multicolumn{2}{|c|}{ Antigout }} & Kolkisin & 2 & 0.32 \\
\hline & & Allopurinol & 1 & 0.16 \\
\hline \multicolumn{2}{|r|}{ Purgative } & $\begin{array}{l}\text { Phenolphthalein, paraffin } \\
\text { liquidum, glycerine }\end{array}$ & 1 & 0.16 \\
\hline Agen inotropic & & Dobutamin & 5 & 0.81 \\
\hline \multirow{3}{*}{ Suplements } & \multirow{2}{*}{ Vitamin } & Vit B com + Vit C & 8 & 1.29 \\
\hline & & Vit B1 + B6 + B12 & 1 & 0.16 \\
\hline & Electrolites & Potassium chloride & 10 & 1.62 \\
\hline
\end{tabular}


Table 4: Evaluation of Blood Lipid Components of Patients

\begin{tabular}{|c|c|c|c|c|c|}
\hline $\begin{array}{c}\text { Time of } \\
\text { Examination }\end{array}$ & Examination & Reference Value & Category & Baseline & Evaluation \\
\hline \multirow{7}{*}{$\begin{array}{l}<1 \text { Month } \\
\quad(n=7)\end{array}$} & \multirow{2}{*}{ Total Cholesterol } & $<200$ & Normal & 0 & 3 \\
\hline & & $>200$ & Hyperlipidemia & 7 & 4 \\
\hline & Trygliceride & $<200$ & Normal & 5 & 6 \\
\hline & \multirow{3}{*}{$\mathrm{HDL}$} & Female : 45-55 & Normal & 1 & 1 \\
\hline & & Male : $<35$ & \multirow{2}{*}{ Hyperlipidemia } & 0 & 0 \\
\hline & & Female $:<45$ & & 0 & 0 \\
\hline & LDL & $<130$ & Normal & 0 & 5 \\
\hline \multirow{8}{*}{ 1-2 Month $(n=57)$} & Total Cholesterol & $>200$ & Hyperlipidemia & 57 & 16 \\
\hline & \multirow{2}{*}{ Tryglicerides } & $<200$ & Normal & 37 & 53 \\
\hline & & $>200$ & Hyperlipidemia & 20 & 4 \\
\hline & \multirow{4}{*}{ HDL } & Male : 35-45 & \multirow{2}{*}{ Normal } & 40 & 41 \\
\hline & & Female : 45-55 & & 15 & 4 \\
\hline & & Male : $<35$ & \multirow{2}{*}{ Hyperlipidemia } & 2 & 1 \\
\hline & & Female $:<45$ & & 0 & 0 \\
\hline & LDL & $<130$ & Normal & 17 & 44 \\
\hline
\end{tabular}

Notes: $\mathrm{n}$ : Numbers of Patients, KT: total cholesterol, TG: triglycerides, HDL: high density lipoprotein, LDL: low density lipoprotein, M: Men, WM: Women.

Table 5: The Average Lipid Profile Score (Before/Baseline and After/Evaluation)

\begin{tabular}{|c|c|c|c|}
\hline \multirow{2}{*}{ Category } & \multicolumn{3}{|c|}{ Averages } \\
\hline & Baseline & Evaluation & Deviation \\
\hline & \multicolumn{3}{|c|}{1 Month $(n=7)$} \\
\hline TG & 158 & 119.7 & 38.28 \\
\hline $\mathrm{HDL}$ & 50.4 & 54.57 & -4.14 \\
\hline \multirow[t]{2}{*}{ LDL } & 141 & 120.5 & 20.7 \\
\hline & \multicolumn{3}{|c|}{ 1-2 Month $(n=57)$} \\
\hline LDL & 144 & 117.67 & 26.19 \\
\hline
\end{tabular}

levels in 44 patients. For HDL examination data showed that HDL levels of CVD patients with hyperlipidemia were men 2 people of 48 patients, who performed $<1$ month checks with 7 patients ( 6 male) 
and 1-2 months with patients as many as 57 people (22 male patients) and those with hyperlipidemia were 2 people. This decrease in HDL levels causes the patient to have hyperlipidemia. For triglyceride examination data showed that triglyceride levels in patients with CVDs with hyperlipidemia were 22 people of 64 patients, patients who performed $<1$ month checks as many as 7 people and those with hyperlipidemia were 2 and 1-2 months with 57 patients and those with hyperlipidemia were 20 .

Table 5 showed the average lipid values of total cholesterol, triglycerides, HDL and LDL patients of cardiovascular diseases before and after treated a statin ie simvastatin. The results of this study showed decreased levels of total lipid cholesterol, LDL and triglycerides and increased levels of HDL lipids.

\section{DISCUSSION}

In the last decade, antihyperlipidemic drugs, especially statins have become standard treatments for patients with heart disease or at risk of CVDs. This can happen because statins can make a significant reduction in the risk of death or cardiovascular events through decreased levels of low-density lipoprotein (LDL) cholesterol. Statins are widely used because they can stabilize plaque, reduce thrombus formation, is anti-inflammatory, and reduce lipid oxidation that has a pleotrophic effect by increasing LDL receptors. Statin utilization should be continued to gain benefit like longterm survival [7].

In the study, we found that the used simvastatin on the mean values of the lipid profile of patients with CVDs before and after using simvastatin showed that there was a decrease in total cholesterol levels, triglycerides, LDL and increased HDL levels.

Simvastatin lowers lipids by inhibiting 3-hydroxy-3methylglutaryl co-enzyme A (HMG-CoA) reductase. HMG-CoA reductase releases precursors of mevalonik acid cholesterol from coenzyme A. Competitive inhibition by simvastatin results in cellular compensatory responses such as elevated HMG-CoA reductase enzyme and Low Density Lipoprotein (LDL) receptor. Due to the increase in HMG-CoA reductase, synthesis of cholesterol cellular only decreased slightly, but mechanism of cholesterol clearance through LDL receptor increased significantly [8]. Simvastatin is very effective to reduce LDL levels and increase HDL levels [9].

Statins can increase LDL receptor activity in the liver as a counter-regulatory mechanism and thus accelerate the clearance of LDL in the blood resulting in a decrease in dose-dependent plasma LDL cholesterol levels. The magnitude of LDL reduction associated with statin therapy in each person varies, but once the patient gets statin therapy, multiplication statin dose will result in a decrease of plasma LDL cholesterol levels up to $6 \%$ and it is also effectively decrease plasma triglycerides depending on the dose usage and this drugs possess slight effect in increasing HDL (5-10\%) which is generally not affected a usage dose [10]. Statins are the most effective lipid-lowering drugs to lower LDL cholesterol (18-55\%), triglycerides (7-30\%), and increase HDL $(5-15 \%)$ and this drug is proven safe without significant side effects [11].

Co-medication with use of drugs other than simvastatin must be done so that the treatment becomes more optimal. Combination therapy with several other classes of drugs such as the used of antiplatetet namely clopidogrel and aspirin which can inhibit platelet aggregation resulting in inhibition of thrombus formation especially in the arterial system. In addition, therapy is needed to treat other risk factors or co-morbidities such as isosorbid dinitrate as antiangina which has an effect on the dilatation of both normal and atherosclerotic coronary arteries [12].

\section{CONCLUSION}

The use of simvastatin drugs reached normal cholesterol levels of 44 patients $(68.75 \%)$ of 64 patients, LDL 49 patients $(80.3 \%)$ of 64 patients, triglyceride 59 patients $(92.19 \%)$ of 64 patients and HDL lipid levels 52 patients (81.25\%) of 64 patients. The usage of simvastatin can lower total lipid cholesterol, LDL and triglyceride levels and increase HDL lipid levels.

\section{ACKNOWLEDGEMENT}

Thanks to the Mathematics and Natural Sciences Faculty of Tadulako University which has funded this research.

\section{REFERENCES}

[1] Ministry of Health. Information Data Center Ministry of Health. Ministry of Health Republic of Indonesia. Jakarta: 2013a.

[2] World Health Organization [homepage on the Internet]. Cardiovascular diseases (CVDs). [uptaded 2018 Sept 23; cited 2016 Oct 12]: Available from: http://www.who.int/ mediacentre/factsheets/fs317/en/

[3] Muttaqin A. Nursing Care of Clients with Impaired Cardiovascular System. Salemba Medika. Jakarta 2008.

[4] Dipiro JT, Talbert RL, Yee GC, Matzke GR, Wells BG, Posey LM. A Pathophysiologic Approach. In: Pharmacotherapy. 7th Edition. New York: The McGraw-Hill Companies 2011; p. 33. 
[5] Ministry of Health. Basic Health Research. Ministry of Health Republic of Indonesia. Jakarta 2013b.

[6] Grundy SM, Cleeman JI, Merz NB, Brewer B, Clark LT, Smith SC, Stone N. Implications of Recent Clinical Trials for the National Cholesterol Education Program Adult Treatment Panel III Guidelines. Circulation 2004.

[7] Munchid A, Umar F, Budiarti LE, Satifa O, Brata C, Bakhtiar L. Pharmaceutical Care for Dislipidemia Disease. Directorate of Community Pharmacy and Clinic. Directorate General of Pharmaceutical and Medical Devices. Ministry of Health 2006.

[8] Page C, Curtis M, Walker M, Hoffman B. Integrated Pharmacology 3rd Ed. Mosby Elsevier 2006.

[9] Spinler SA, Johnson NE. Comparative evaluation of the safety and efficacy of HMG-CoA reductase inhibitor monotherapy in the treatment of primary hypercholesterolemia. Ann Pharmacotherapy 1995.

[10] Dipiro JT, Talbert RL, Yee GC, Matzke GR, Wells BG, Posey LM. Pharmacotherapy Handbook Nineth. USA: McGraw-Hill Company 2015.

[11] Jellinger PS, Smith DA, Mehta AE, Ganda O, Handelsman $Y$, Rodbard HW, Shepherd MD, Seibel JA. AACE Task Force for the Management of Hyperlipidemia and Prevention of Atherosclerosis Writing Committee. Endocr Pract 2012.

[12] Association of Indonesian Cardiovascular Specialist Doctors. Guidelines for the Treatment of Hyperlipidemia in Cardiovascular Disease. First Edition. Jakarta: Association of Cardiovascular Specialist Doctors Indonesia 2015.

Received on 18-09-2018 